\title{
LETTER TO THE EDITOR \\ Experiences from nutritional rehabilitation among under 5 children from a remote mountain area of Nepal
}

\author{
S Pantha ${ }^{1}$, S Hutter ${ }^{2}$, P Gartoulla ${ }^{3}$ \\ ${ }^{1}$ National Academy of Medical Education, Mahabouddha, Kathmandu, Nepal \\ ${ }^{2}$ International Nepal Fellowship, Jumla, Nepal \\ ${ }^{3}$ Nepal Institute of Health Sciences, Tusal, Bouddha, Kathmandu, Nepal
}

Submitted: 12 November 2011; Revised: 20 February 2012; Published: 18 May 2012

Pantha S, Hutter S, Gartoulla P

Experiences from nutritional rehabilitation among under 5 children from a remote mountain area of Nepal Rural and Remote Health 12: 2007. (Online) 2012

Available: http://www.rrh.org.au

\section{Dear Editor}

Protein energy malnutrition is a cause of under-five morbidity and mortality in developing countries ${ }^{1,2}$. Nepal has a high rate of child malnutrition with approximately half (49\%) stunted and 39\% underweight ${ }^{3}$. In addition, malnutrition accounts for approximately half of all children's deaths ${ }^{4}$.

The mountain district of Jumla is situated in the midwest region of Nepal, approximately $700 \mathrm{~km}$ north-west of the capital Kathmandu. Currently air transport is the only means of transport to and from the district due to the poor road conditions $^{3,5}$. The majority of people in Jumla live in poverty line and there is a high prevalence of malnutrition ${ }^{5}$.
The International Nepal Fellowship (INF) is a nongovernment organization established in 1952. It has been involved in community health empowerment interventions and other development work in Nepal with the aim of achieving sustainable improvements in health and quality of life. In 2006, a 6 bed nutrition rehabilitation centre was established in its Jumla premises ${ }^{6}$. We recently studied the effect of nutritional rehabilitation among malnourished children in the INF centre.

In this hospital-based study, we retrospectively analyzed the data on 82 malnourished children admitted to the centre during the year July 2008 to June 2009. These children were provided with nutritional supplementation and treatment for co-morbid medical conditions free of cost. 
Baseline information and anthropometric measurements were taken on admission. A rehabilitation officer evaluated the parents' understanding of healthy feeding and the current feeding practices in the family. Co-morbid medical conditions were addressed in collaboration with the medical officer from district hospital.

The average duration of inpatient stay was 14 days. Malnutrition was more prevalent in boys than in girls (1.8:1); however, due to gender discrimination in the community, boys were more likely to be presented for treatment than girls. The growth status of more than one-third of the children (35\%) lagged by at least one year of age, and 6.2\% children were 6 months behind their actual ages. Approximately $14 \%$ had edema at the time of presentation. Diarrheal diseases and acute respiratory tract infections were the leading co-morbidities among these malnourished children at $49 \%$ and $23 \%$, respectively. There were two deaths $(2.4 \%)$, both due to pneumonia.

Nutritional supplementation was found to be highly effective in reducing malnutrition-associated morbidity and mortality. Locally available food resources, including pulses, legumes, barley, corn, wheat, soya flour and eggs were used to prepare calorie-rich food. A high level of hygiene was ensured. Nutritional supplementation was provided according to the WHO recommendations for malnutrition, with $75 \mathrm{Kcal}$ per $100 \mathrm{~mL}(\mathrm{~F} 75 ; 315 \mathrm{~kJ} / 100 \mathrm{~mL})$ in the initial treatment phase and $100 \mathrm{Kcal}$ per $100 \mathrm{~mL}(\mathrm{~F} 100 ; 420 \mathrm{~kJ} / 100 \mathrm{~mL})$ in the rehabilitation phase ${ }^{7}$.

The kin (usually, mother) of the malnourished children were shown how to make nutritious food from locally available resources and how to provide a balanced diet. Group discussions were conducted on malnutrition and its consequences and the importance of a balanced diet in childhood. For 5 months after discharge INF field workers followed up the children with 3 home visits to ensure effective implementation of the nutritional supplementation.

In summary, diarrheal diseases and respiratory tract infections form the leading cause of morbidity and mortality among malnourished children in Nepal. Rehabilitative services can effectively manage malnutrition and co-morbidities and also reduce mortality in these children. In addition, the provision of such services also provides an opportunity to teach parents and caretakers how to prepare nutritious food from locally available resources in a cost-effective and culturally acceptable way.

\section{Sandesh Pantha MBBS ${ }^{1}$, Susanne Hutter $\mathrm{MPH}^{2}$ and Pragya Gartoulla $\mathbf{M P H}^{3}$ \\ ${ }^{1}$ District Hospital and ${ }^{2}$ International Nepal Fellowship, Jumla, and \\ ${ }^{3}$ Nepal Institute of Health Sciences, Stupa College of Health Sciences, Kathmandu, Nepal}

\section{References}

1. Rayhan MI, Khan M. Factors causing malnutrition among under five children in Bangladesh. Pakistan Journal of Nutrition 2006; 5(6): 258-262.

2. Sah N. Determinants of child malnutrition in Nepal: A case analysis from Dhanusha, Central Terai of Nepal. Journal of Nepal Health Research Council 2004; 2(2): 50-54.

3. Ministry of Health and Population, New ERA and Macro International Inc. Nepal Demographic and Health Survey 2006. Kathmandu: MOHP, New ERA and Macro International Inc, 2007. Available: www.measuredhs.com.

4. Rai SK, Hirai K, Abe A, Ohno Y. Infectious diseases and malnutrition status in Nepal: an overview. Malaysian Journal of Nutrition 2002; 8(2): 191-200.

5. Nepal Safe Motherhood Project. Need Assessment Report For phase 2: Design and Planning. Kathmandu. (Online) 1999. Available: http:/www.nsmp.org (Accessed 10 April 2012). 


\section{Fiural-and-Remote-Health}

The International Electronic Journal of Rural and Remote Health Research, Education Practice and Policy

6. International Nepal Fellowship. INF Nepal. (Online) 2012. Available: http://www.inf.org/inf-nepal (Accessed 18 January 2012).
7. WHO. Module 4 feeding. In: Training course on the management of severe malnutrition. (Online) 1999. Available: http:// whqlibdoc.who.int/hq/2002/WHO_NHD_02.4_Module4_eng.p df (Accessed 10 April 2012). 